\title{
Evaluation of Chemical Properties of Cold Pressed Ficus Carica Seed Oil
}

\author{
Hamide Filiz Ayyildiz ${ }^{1}$, Raziye Nur Ozcicek ${ }^{2}$ and Huseyin Kara ${ }^{2} *$ \\ ${ }^{1}$ Selcuk University, Faculty of Pharmacy, Department of Basic Pharmaceutical Sciences, 42075 Campus, Konya, \\ Turkey. \\ ${ }^{2}$ Selcuk University, Faculty of Science, Department of Chemistry, 42075 Campus, Konya, Turkey. \\ *Corresponding Author Email: huskara@gmail.com \\ Received 30 April 2021, Revised 18 June 2021, Accepted 23 June 2021
}

\begin{abstract}
Free fatty acid, peroxide value, conjugated diene and triene, chlorophyll, $\beta$-carotene, fatty acid composition, triglyceride, tocol (tocopherol and tocotrienol) compositions, sterol, wax and total polymeric compound amounts of cold pressed Ficus carica seed oil were evaluated by using chromatographic and spectrometric methods in this study. While the \% free fatty acid of cold pressed ficus carica seed oil was $0.76 \pm 0.06$, the peroxide value was found as $1.06 \pm 0.09$ meqO $\mathrm{O}_{2} / \mathrm{kg}$. It also had low content of conjugated diene and triene amounts, chlorophyll, wax and total polymeric compounds. The obtained results demonstrated that cold pressed ficus carica seed oil had rich linolenic and linoleic acid, and contained high amounts of Linoleic- LinolenicLinolenic, Linolenic- Linolenic- Linolenic, Olenic- Linoleic- Linolenictriglycerides. Cold pressed ficus carica had a high content of $\beta$-carotene (4114.9 ppm), total tocol (1006 ppm) and sterol $(7250.83 \mathrm{ppm})$. The obtained results showed that ficus carica seed oil is a product with superior properties due to its high nutritional value and beneficial phytochemicals. Therefore this oil can be an alternative to vegetable oils and used as a medical product.
\end{abstract}

Keywords: Ficus carica seed oil, Cold pressed, Fatty acid composition, Tocopherol, Triglyceride composition, Sterol, Wax, Polymeric compounds.

\section{Introduction}

Ficus Carica, which is cultivated in a wide geographical area extending from Turkey to Afghanistan is a member of the Moraceae family and contains high amounts of carbohydrates, vitamins, dietary fiber, minerals and oils [1-3]. Ficus Carica seeds contain fixed oil between $21.54 \%-28.52 \%$ [4]. These seeds have valuable essential fatty acids, tocopherols \& tocotrienols and triglycerides. Edible oils are generally obtained from oilseeds using dehulling, solvent extraction, pressing and separation methods. During the production of these oils, various undesirable substances are formed due to temperature, humidity, pressure, use of solvents and the quality decreases [5-7]. Cold pressing is a method used instead of industrial applications and no heat is applied to the raw material as in the screw pressing process. Cold pressing doesn't have a negative effect on the beneficial components of the edible oils. In addition, no organic solvents that would be chemical contaminants in the product are used in cold pressing $[8,9]$. Therefore, cold pressing oils contain more bioactive components such as lecithin (phospholipids), vitamins (tocopherols / vitamin E, etc.), phytosterols, lignin, squalene, organo minerals, lipoproteins $[6,8,10-12]$. 
Fatty acid composition, triglyceride (TG), tocol (tocopherol and tocotrienol) compositions, sterol, wax, total polymeric compounds, chlorophyll, $\beta$-carotene, peroxide value, conjugated diene and triene amounts for cold pressed oils are very important parameters for nutritional value, oil quality and shelf life $[5,6,13]$. In many previous studies, it has been found that Ficus Carica seed oil is an important source of linolenic acid, tocol and sterol, which have been proven to prevent many diseases such as obesity, cardiovascular and some cancer types [14-17].

The free fatty acid (FFA), peroxide value (PV), chlorophyll, conjugated diene (CD) and triene (CT) amounts are important oil components related to oxidative stability $[13,18]$. The amounts of these components are important criteria used for the quality and consumability of oil [5]. The amounts of these ingredients must be within the limit values set by the Turkish Food Codex and relevant codex [19]. The goal of this study was to investigate chemical properties such as FFA, $\mathrm{PV}, \mathrm{CD}$ and $\mathrm{CT}$, chlorophyll, $\beta$-carotene, fatty acid composition, triglyceride (TG), tocol (tocopherol and tocotrienol) compositions, sterol, wax, total polymeric compound amounts of cold pressed Ficus carica seed oil in Turkey. Although there are previous reports on the fatty acid, tocol and sterol compositions of cold pressed seed Ficus carica oil, this is the first study that reports the identification and quantification of triglyceride, wax and total polymeric compounds.

\section{Materials and Methods Chemicals and Reagents}

All chemicals and reagents for analysis were of analytical grade and purchased from Merck (Darmstadt, Germany) and BDH (Poole, UK). A fatty acid methyl ester (FAME) mix (37-component FAME blend), triglyceride standards kit (TRI19-1KT,) and tocopherol $(\alpha-\mathrm{T}, \quad \beta-\mathrm{T}, \quad \gamma-\mathrm{T}, \quad \delta-\mathrm{T}) \quad$ and tocotrienols $\quad(\mathrm{a}-\mathrm{T} 3, \quad \beta-\mathrm{T} 3, \quad \gamma-\mathrm{T} 3, \quad \delta$-T3) standards were purchased from Supelco (Bellefonte, PA) and Sigma Aldrich. Ficus carica seed was obtained from İzmir, Turkey.

\section{Oil Extraction by Cold Press Procedure}

Dry seeds $(1 \mathrm{~kg})$ were extracted using cold pressing machine (Ecotoner 01, TOKULLAR Agro Products Ltd. Co., Antalya, Turkey). Ficus carica seed oil was obtained in cold press machine at $2 \mathrm{~mm}$ head diameter, $70{ }^{\circ} \mathrm{C}$ temperature, $20 \mathrm{rpm}$ engine speed.

\section{Determination of Free Fatty Acid}

The \% FFA content of the oil sample was determined as \% oleic acid using the standard AOCS Ca-5a-40 method [20]. Briefly, $1 \mathrm{~g}$ of sample was solved $15 \mathrm{~mL}$ of neutral ethyl alcohol and titrated with $0.01 \mathrm{~N}$ $\mathrm{NaOH}$ solution along with phenolphthalein indicator until a pink color was formed. The \%FFA amount was calculated by reading $\mathrm{NaOH}$ consumption. It was performed three times for each oil sample.

\section{Determination of Peroxide Value (PV)}

The PV was determined using the standard AOCS Cd-8b-90 method [20]. The peroxide value is defined as meqO $/ 2 / \mathrm{kg}$ of oil and is a measure of the hydroperoxide content. Briefly, $1 \mathrm{~g}$ of sample was solved in $1 \mathrm{~mL}$ of chloroform and $1.5 \mathrm{~mL}$ of acetic acid and then $0.1 \mathrm{~mL} \mathrm{KI}$ was added and left in the dark for 3 minutes. After, $25 \mathrm{~mL}$ of distilled water and 3 drops of $1 \%$ starch solution were added and titrated with $0.002 \mathrm{~N}$ adjusted $\mathrm{Na}_{2} \mathrm{~S}_{2} \mathrm{O}_{3}$ until the color became clear. It was performed in triplicate for each oil sample. 
Determination of Conjugated Diene and Triene

$\mathrm{CD}$ and CT amounts of ficus carica seed oil were determined according to The European Communities official method using a double-beam path UV-visible spectrophotometer [21]. $0.05 \mathrm{~g}$ oil sample, which dissolved in $10 \mathrm{~mL}$ isooctane was filled into the sample cuvette. Absorbance values were read at 232 and $270 \mathrm{~nm}$ wavelengths by a Shimadzu UV-1800 spectrophotometer (Shimadzu Europe GmbH, Germany) and were used to calculate the $\mathrm{CD}$ and $\mathrm{CT}$ amounts.

\section{Determination of Chlorophyll and $\beta$-carotene Amounts}

Chlorophyll and $\beta$-carotene amounts in the ficus carica seed oil were determined using a dual-beam Shimadzu UV-1800 spectrophotometer (Shimadzu Europe $\mathrm{GmbH}$, Germany) [22]. The oil sample dissolved in isooctane was filled into the sample cuvette without any pre-treatment and spectrum scanning was performed.

$$
\begin{aligned}
& \text { Chlorophyl }(\mathrm{ppm})=\frac{\left(\mathrm{b}-\frac{(\mathrm{a}+\mathrm{c})}{2}\right) \times 1000}{0} .1 \\
& \beta-\operatorname{carotene}(\mathrm{ppm})=\frac{\mathrm{d} \times 1000}{0} .261
\end{aligned}
$$

a: Absorbance at the starting point of the chlorophyll peak at $650 \mathrm{~nm}$

b: Absorbance at the peak of the chlorophyll peak at $650 \mathrm{~nm}$

c: Absorbance at the endpoint of the chlorophyll peak at $650 \mathrm{~nm}$

$\mathrm{d}$ : Absorbance at the peak of $\beta$-carotene peak at $450 \mathrm{~nm}$

\section{Fatty Acid Compositions Analysis by GC- FID}

$0.1 \mathrm{~g}$ of oil was derivatized with $1 \mathrm{~mL}$ of $2 \mathrm{~N}$ methanolic $\mathrm{KOH}$ solution for $10 \mathrm{~min}$ at room temperature. Later $7 \mathrm{~mL}$ of $\mathrm{n}$-hexane was added to extract FAME and the mixture was shaken vigorously for $1 \mathrm{~min}$. The upper phase of the solution, which was centrifuged at $2000 \mathrm{~g}$ for $10 \mathrm{~min}$, was taken and dried with $1 \mathrm{~g}$ of $\mathrm{Na}_{2} \mathrm{SO}_{4}$ [23-26].

Fatty acid composition of the oil was determined by using an Agilent 7890 series gas chromatography-flame ionization detector (GC-FID) onto an HP-88 column (100 m, 0.25 $\mathrm{mm}, 0.25 \mu \mathrm{m}$, Agilent Technologies, USA). 1 $\mu \mathrm{L}$ FAME were injected at a split ratio of 100:1. The carrier gas was hydrogen at a flow rate of $1.3 \mathrm{~mL} / \mathrm{min}$. The oven temperature was programmed as follows: initial oven temperature of $50{ }^{\circ} \mathrm{C}$ was held for $10 \mathrm{~min}$ and increased to $250{ }^{\circ} \mathrm{C}$ at $4{ }^{\circ} \mathrm{C} / \mathrm{min}$ and was held at $250{ }^{\circ} \mathrm{C}$ for $10 \mathrm{~min}$. Injector and detector temperatures were kept at $250{ }^{\circ} \mathrm{C}$. The identification of FAMEs was based on retention times compared to those of the standard FAME mix. Fatty acid analysis were performed three times and the mean values were reported as a percentage.

\section{Triglyceride Composition Analysis by HPLC}

The triglyceride composition of the oils was determined by an Agilent 1200 series HPLC system consisted of a UV detector set at wavelengths of $215 \mathrm{~nm} .1 \mathrm{~g}$ of oil was dissolved in $10 \mathrm{~mL}$ acetone and injected into the ACE 5 C18 column $(250 \times 4 \mathrm{~mm}, 5 \mu \mathrm{m}$ particle size, Advanced Chromatography Technologies, Aberdeen, Scotland). An isocratic elution system with acetoneacetonitrile (1:1) mixture was used at a flow rate of $1.5 \mathrm{~mL} / \mathrm{min}[20,26]$.

\section{Tocols (Tocopherols and Tocotrienols) Analysis by HPLC}

The tocols were analyzed by an Agilent 1200 series HPLC system consisted of FLD detector adjusting $295 \mathrm{~nm}$ for excitation and $320 \mathrm{~nm}$ for emission. $1 \mathrm{~g}$ of oil was 
dissolved in $10 \mathrm{~mL}$ of hexane and injected into the LICHROSPHER $(5 \mu \mathrm{m}$ Si 100 250x4.0 mm) column. An isocratic elution system with n-hexan/isopropanol (96:4) mixture was used at a flow rate of $1.0 \mathrm{~mL} / \mathrm{min}$ [6]. The tocols were measured by the linear calibration curve with respect to peak areas compared to external standards.

\section{Sterol Composition Analysis by GC-FID}

Sterol analysis was carried out by the International Olive Oil Council (COI) official method [27]. Briefly, $500 \mu \mathrm{L}$ of $\alpha$-cholestanol $(100 \mathrm{mg} / \mathrm{L})$ used as internal standard was placed in a $50 \mathrm{~mL}$ flask and the solvent was removed. After that, $5 \mathrm{~g}$ of oil sample and 50 $\mathrm{mL}$ of $1 \mathrm{~N}$ ethanolic $\mathrm{KOH}$ were added flask. The saponification was carried out by boiling at $90{ }^{\circ} \mathrm{C}$ for $1 \mathrm{~h}$ under reflux. The saponified part was extracted with $100 \mathrm{~mL}$ of water and $100 \mathrm{~mL}$ of diethyl ether and, the separated organic phase was washed 3 times with $50 \mathrm{~mL}$ of water. At the end of the washing process, the solvent of the organic phase separated from the aqueous phase was removed. The sample, whose solvent was removed, was redissolved in $1 \mathrm{~mL}$ of chloroform. $200 \mu \mathrm{L}$ was taken from the dissolved part and solvent was removed. $250 \mu \mathrm{L}$ anhydrous pyridine and 250 $\mu \mathrm{L}$ BSTFA silylation reagent were added on it. The mixture was subjected to silylation at room temperature for $5 \mathrm{~min}$ and at $60{ }^{\circ} \mathrm{C}$ for $20 \mathrm{~min}$.

\footnotetext{
Sterols in the oil were determined using an Agilent 7890 series gas chromatography-flame ionization detector (GC-FID) onto HP-5MS (30 m x $0.25 \mathrm{~mm} \mathrm{x}$ $0.25 \mu \mathrm{m}$, Agilent Technologies, USA) column. The silylated sterols were injected at a flow rate of $1 \mu \mathrm{L}$. The carrier gas was hydrogen at $1 \mathrm{~mL} / \mathrm{min}$. The oven temperature was programmed as follows: initial oven temperature of $100{ }^{\circ} \mathrm{C}$ was held for 0 min and increased to $300{ }^{\circ} \mathrm{C}$ at $5{ }^{\circ} \mathrm{C} / \mathrm{min}$ and was held
}

at $300{ }^{\circ} \mathrm{C}$ for $20 \mathrm{~min}$. Injector and detector temperatures were kept at $250{ }^{\circ} \mathrm{C}$ and $325^{\circ} \mathrm{C}$, respectively.

\section{Wax Composition Analysis by GC-FID}

Wax analysis was carried out by the International Olive Oil Council (COI) official method [27]. Briefly, $15 \mathrm{~g}$ of silica gel, that was slurried in hexane, was filled into the glass column and was cleaned by passing 30 $\mathrm{mL}$ of hexane through the column. A mixture of $500 \mathrm{mg}$ oil sample, $500 \mathrm{~mL}$ lauryl arachidate used as internal standard and 100 $\mu \mathrm{L}$ of $1 \%$ Sudan-I used as indicator was dissolved in $2 \mathrm{~mL}$ hexane. The prepared mix solution was transferred to the column and was eluted with the hexane/ethyl ether (99:1) mobile phase in $\sim 10-15$ drops in $10 \mathrm{~s}$. The elution process was continued until the red colored Sudan-I indicator was seen at the end of the column. The eluted part was collected in a beaker. The sample, whose solvent was removed, was re-dissolved with $2 \mathrm{~mL}$ of $\mathrm{n}$ heptane.

Waxes in the oil were determined using an Agilent 7890 series gas chromatography-flame ionization detector (GC-FID) onto RTX -5 (15 m x $0.18 \mathrm{~mm} \mathrm{x}$ $0.20 \mu \mathrm{m})$ column. The waxes were injected at $1 \mu \mathrm{L}$. The carrier gas was helium at a flow rate of $2.4 \mathrm{~mL} / \mathrm{min}$. The oven temperature was programmed as follows: initial oven temperature $80{ }^{\circ} \mathrm{C}$ was held for $0 \mathrm{~min}$, increased to $200^{\circ} \mathrm{C}$ at $28^{\circ} \mathrm{C} /$ minute for $1 \mathrm{~min}$, was kept at $340{ }^{\circ} \mathrm{C}$ at $2.8{ }^{\circ} \mathrm{C} / \mathrm{min}$ and was held at $340{ }^{\circ} \mathrm{C}$ for $25 \mathrm{~min}$. The injector temperature was programmed as follows: oncolumn inlet temperature was raised to $80{ }^{\circ} \mathrm{C}$ for $0 \mathrm{~min}$ and increased to $320{ }^{\circ} \mathrm{C}$ at 40 ${ }^{\circ} \mathrm{C} / \mathrm{min}$. The detector temperature was kept at $350{ }^{\circ} \mathrm{C}$. The flow rates of dry air and hydrogen gas were 300 and $30 \mathrm{~mL} / \mathrm{min}$, respectively. 
Total Polymeric Compounds Analysis by HPSEC

The total polymeric compounds were analyzed by using an Agilent 1200 series HPLC system consisted of a refractive index $\left(35{ }^{\circ} \mathrm{C}\right)$ detector. $1 \mathrm{~g}$ of oil sample was dissolved in $10 \mathrm{~mL}$ of tetrahydrofuran (THF) and injected into guard HPSEC column (PLGel $\left.100 \mathrm{~A}^{\circ}\right)(5 \mathrm{~cm} \times 7.6 \mathrm{~mm}$ id, $5 \mu \mathrm{m})$ and HPSEC column (PL-Gel $\left.100 \mathrm{~A}^{\circ}\right)(30 \mathrm{~cm}$ x 7.6 $\mathrm{mm}$ id, $5 \mu \mathrm{m})$. An isocratic elution system with tetrahydrofuran was used at a flow rate of $1 \mathrm{~mL} / \mathrm{min}$. Results were reported as a percentage [28].

\section{Data Analysis}

All experiments were replicated at least three times. The statistical evaluation of the results was carried out using Microsoft Excel, 2007. Statistical significance was declared at $\mathrm{P}<0.05$.

\section{Results and Discussion}

Ficus carica seed was found to contain $26.44 \%$ fixed oil. The obtained result was in agreement with the previous report by Hssaini et al., [4].

FFA and PV are accepted as important quality indicators in the production, storage and consumption of vegetable oils. FFA and PV contents were \% $0.76 \pm 0.06$ oleic acid and $1.06 \pm 0.09 \mathrm{megO}_{2} / \mathrm{kg}$ oil, respectively. In the edible oils communiqué published by the Turkish Standards Institute, peroxide values should be maximum of $15 \mathrm{meqO}_{2} / \mathrm{kg}$ oil for extra virgin and cold pressed oils [19]. When the obtained FFA and PV contents were examined, it was seen that these values were appropriate in terms of the consumability of the oil.

$\mathrm{CD}$ and CT amounts of ficus carica seed oil were found to be 0.02 and 0.03 , respectively. When the obtained results were evaluated, it has been observed that values were compatible with PV analysis and very low.

Chlorophyll and carotene contents are among the most important parameters affecting the shelf life of oils. The amount of chlorophyll and $\beta$-carotene in ficus carica seed oil was determined as a result of spectrum scanning between $200-800 \mathrm{~nm}$ and found to be $25 \mathrm{ppm}$ and $4114.9 \mathrm{ppm}$, respectively. The results showed that the amount of $\beta$-carotene was high and the amount of chlorophyll was low in cold pressed ficus carica seed oil.

The fatty acid composition of the cold pressed ficus carica seed oil was shown in Table 1. A total of 13 different fatty acids were determined in cold pressed ficus carica seed oil. The obtained results showed that cold pressed ficus carica seed oil was a rich source of polyunsaturated fatty acids. The linoleic $(33.74 \%)$ and linolenic acid $(34.05 \%)$ were major fatty acids in ficus carica seed oil, which were similar to previous reported by Güven et al., [29] and Hssaini et al., [4]. Oleic acid (C18:1), a member of monounsaturated fatty acids, was found to be $19.61 \%$ in ficus carica seed oil, which was in agreement with previous reports [3, 4, 29]. It also contained saturated fatty acids such as palmitic acid (8.0 $\%)$ and stearic acid (3.72\%).

The results of the triglyceride composition analysis for cold pressed ficus carica seed oil was given in Table 1 . Triglycerides are the most concentrated energy source in the diet and serve as carriers for fat-soluble vitamins such as A, D, E and $\mathrm{K}$ [25]. The most abundant triglycerides in cold pressed ficus carica seed oil were LLnLn, LnLnLn, OLLn, LLLn and PLLn. The LLnLn (20.44\%) was found to be a major triglyceride in ficus carica seed oil. LnLnLn, LLLn, LLL, 
OLLn and PLLn containing linolenic and linoleic acid were determined for 17.59, $13.57,4.84,16.63$ and $9.02 \%$, respectively, of the total triglycerides.

Although studies on ficus carica seed oil have been comprehensively searched in the literature, no studies have been found about triglyceride composition analysis. Therefore, this study is the first for the triglyceride composition of ficus carica seed oil. For this reason, our study gives more information about the composition of triglycerides in ficus carica seed oil compared to the reported many studies [3, 4, 29].

Table 1. Fatty acid and triglyceride compositions of cold pressed ficus carica seed oil.

\begin{tabular}{|c|c|c|c|c|c|c|}
\hline \multicolumn{5}{|c|}{ Fatty Acid Composition (\%) } & \multicolumn{2}{|c|}{ Triglyceride Composition (\%) } \\
\hline & Present Study & Nakilcioğlu-Taş [3] & Hssaini et al. [4] & Güven et al. [29] & & Present Study \\
\hline C16:0 & $8.00 \pm 0.02$ & $3.58-7.40$ & $8.539-9.05$ & $5.0-9.0$ & LnLnLn & $17.59 \pm 0.73$ \\
\hline C16:1 & $0.05 \pm 0.01$ & $0.05-0.06$ & $0.059-0.162$ & - & LLnLn & $20.44 \pm 0.70$ \\
\hline $\mathrm{C} 17: 0$ & $0.07 \pm 0.00$ & 0.06 & $0.036-0.053$ & - & LLLn & $13.57 \pm 0.39$ \\
\hline C18:0 & $3.72 \pm 0.01$ & $2.97-3.73$ & $2.594-3.302$ & $2.0-4.0$ & LLL & $4.84 \pm 0.13$ \\
\hline $\mathrm{C} 18: 1 \mathrm{cis}$ & $19.61 \pm 0.01$ & $16.82-17.79$ & $13.438-15.642$ & $14.0-24.0$ & OLLn & $16.63 \pm 0.50$ \\
\hline $\mathrm{C} 18: 2$ cis & $33.74 \pm 0.06$ & $31.80-37.95$ & $28.905-33.866$ & $20.0-35.0$ & PLLn & $9.02 \pm 2.98$ \\
\hline C20:0 & $0.44 \pm 0.00$ & $0.02-0.03$ & $0.066-0.099$ & Max 0.7 & OLL & $6.62 \pm 0.18$ \\
\hline $\mathrm{C} 18: 3 \mathrm{n} 3$ & $34.05 \pm 0.01$ & $37.87-41.80$ & $38.436-43.753$ & $32.0-50.0$ & PLL & $5.21 \pm 2.48$ \\
\hline $\mathrm{C} 20: 2$ & $0.05 \pm 0.01$ & - & - & - & OOL & $2.93 \pm 0.62$ \\
\hline $\mathrm{C} 22: 0+\mathrm{C} 20: 3 \mathrm{n} 6$ & $0.12 \pm 0.00$ & - & - & Max 0.5 & POL+StLL & $3.26 \pm 0.61$ \\
\hline $\mathrm{C} 23: 0$ & $0.03 \pm 0.03$ & - & - & - & PPL & $0.06 \pm 0.10$ \\
\hline $\mathrm{C} 24: 1$ & $0.10 \pm 0.01$ & - & - & - & OOO & $1.28 \pm 0.04$ \\
\hline $\mathrm{C} 22: 6$ & $0.01 \pm 0.02$ & - & - & - & StOL & $0.04 \pm 0.03$ \\
\hline
\end{tabular}

Table 2. Tocol and sterol compositions of cold pressed ficus carica seed oil.

\begin{tabular}{|c|c|c|c|c|c|c|}
\hline \multicolumn{4}{|c|}{ Tocopherol and tocotrienol (ppm) } & \multicolumn{3}{|c|}{ Sterol (ppm) } \\
\hline & Present Study & Güven et al. [29] & Baygeldi et al. [31] & & Present Study & Güven et al. [29] \\
\hline$\alpha-\mathrm{T}$ & $23.87 \pm 0.35$ & 157 & 460 & Campesterol & $51.47 \pm 1.16$ & 194.71 \\
\hline$\beta-\mathrm{T}$ & ND & - & - & Stigmasterol & $3660.42 \pm 3.01$ & 141.97 \\
\hline$\gamma-\mathrm{T}$ & $955.4 \pm 4.36$ & 4267 & 3918.9 & $\beta$-Sitosterol & $2398.00 \pm 2.31$ & 4326.05 \\
\hline$\delta-\mathrm{T}$ & $20.73 \pm 4.05$ & 147 & 76.5 & 5-Avenesterol & $834.80 \pm 0.83$ & 1312.21 \\
\hline$\alpha-\mathrm{T} 3$ & $2.79 \pm 0.16$ & - & - & Stigmastadien & $54.54 \pm 1.23$ & 83.35 \\
\hline$\beta-\mathrm{T} 3$ & $3.24 \pm 0.46$ & - & - & Total & $7250.83 \pm 8.59$ & 6516.20 \\
\hline$\gamma-\mathrm{T} 3$ & ND & - & - & & & \\
\hline$\delta-\mathrm{T} 3$ & ND & - & - & & & \\
\hline Total T & $1000 \pm 2.23$ & 4571 & 4014.4 & & & \\
\hline Total T3 & $6.03 \pm 0.60$ & - & - & & & \\
\hline Total Tocol & $1006 \pm 0.60$ & 4571 & 4014.4 & & & \\
\hline
\end{tabular}

Tocopherols and tocotrienols (Tocol) found naturally in vegetable oils are important antioxidants. The oxidative stability of oils is directly related to presence of these compounds [30]. Tocol values for cold pressed ficus carica seed oil sample were given in Table 2. Cold pressed ficus carica seed oil had $\gamma$ - tocopherol with $955.4 \mathrm{ppm}$ as 
the basic component. The $\alpha$-tocopherol (23.87 ppm) and $\delta$-tocopherol (20.73 ppm) were prominent tocols in cold pressed ficus carica seed oil. Cold pressed ficus carica seed oil also contained small amounts of $\alpha$-tocotrienol (2.79 ppm) and $\beta$-tocotrienol (3.24 ppm). Total tocol content in cold pressed ficus carica seed oil (1006 ppm) was found lower than that reported by Güven et al. [29] (4571 ppm) and by Baygeldi et al., [31] (4041.4 ppm). $\beta$ tocopherol, $\gamma$-tocotrienol and $\delta$ - tocotrienol were not detected in cold pressed ficus carica seed oil.

Sterol composition values for cold pressed ficus carica seed oil were given in Table 2. Cold pressed ficus carica seed oil contained stigmasterol with $3660.42 \mathrm{ppm}$ as the major sterol. It has been determined that the $\beta$-sitosterol content, which is the most found in vegetable oils, was 2398 ppm in oil. Cold pressed ficus carica seed oil also contained 5-avenesterol (834.80 ppm), stigmastadien (54.54 ppm) and campesterol (51.47 ppm). When the obtained sterol composition results were examined, the total sterol amount was $7250.83 \mathrm{ppm}$, which was similar to previously reported by Güven et al., [29] (6516.20 ppm).

Waxes (generally C36-C50) formed by esterification of long-chain fatty acids and alcohols are known to reduce the freezing point of oils, create a crystalline structure, and reduce their light transmission and solubility [32]. Wax composition chromatogram and values for cold pressed ficus carica seed oil were given in Fig.1 and Table 3, respectively. Cold pressed ficus carica seed oil contained $\mathrm{C}_{40}$ with $76,56 \mathrm{ppm}$ and $\mathrm{C}_{42} 213,83 \mathrm{ppm}$. $\mathrm{C}_{44}$ and $\mathrm{C}_{46}$ waxes were absent in cold pressed ficus carica seed oil. When the results of the wax composition obtained were examined, the total amount of wax in cold pressed ficus carica seed oil was 290.39 ppm. Although studies on ficus carica seed oil have been comprehensively searched in the literature, no studies have been found about wax composition analysis. Therefore, this study is the first for the wax composition of ficus carica seed oil.

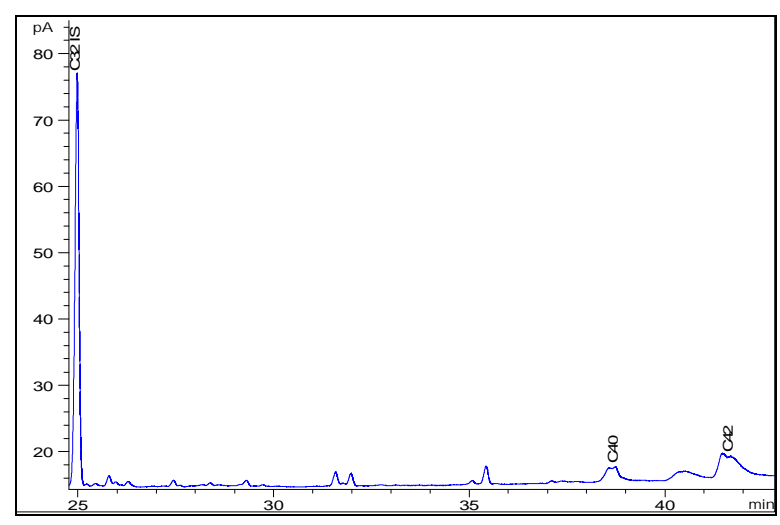

Figure 1. Wax composition chromatogram of ficus carica seed oil

Table 3. Polymeric substance and wax compositions of cold pressed ficus carica seed oil.

\begin{tabular}{lclc}
\hline \multicolumn{2}{c}{ Wax Composition (ppm) } & \multicolumn{2}{c}{ Polymeric Substance (\%) } \\
\hline $\mathrm{C}_{40}$ & $76.56 \pm 12.54$ & Polymeric & $0.01 \pm 0.01$ \\
$\mathrm{C}_{42}$ & $213.83 \pm 34.51$ & Triacylglycerol & $96.92 \pm 0.18$ \\
$\mathrm{C}_{44}$ & $\mathrm{ND}$ & Diacylglycerol & $1.62 \pm 0.24$ \\
$\mathrm{C}_{46}$ & $\mathrm{ND}$ & Monoacylglycerol & $0.52 \pm 0.03$ \\
Total & $290.39 \pm 48.13$ & FFA & $0.94 \pm 0.04$ \\
\hline *ND: Not detected & &
\end{tabular}

In order to determine the total polymeric compound content of cold pressed ficus carica seed oil sample, analysis was carried out using HPSEC columns in the HPLC device. The polymeric and nonpolymeric substances in the oil were allowed to exit the column based on size exclusion. The total polymeric compound chromatogram and amount for cold pressed ficus carica seed oil sample was given in Fig.2 and Table 3, respectively. The obtained results showed that cold pressed ficus carica seed oil had trace amount of polymeric compound with $0.01 \%$, diacylglycerol with $1.62 \%$, monoacylglycerol with $0.52 \%$ and FFA with $0.94 \%$. Although studies on ficus carica seed oil have been comprehensively searched in the literature, no 
studies have been found about polymeric compound analysis. Therefore, this study is the first for polymeric compound of ficus carica seed oil.

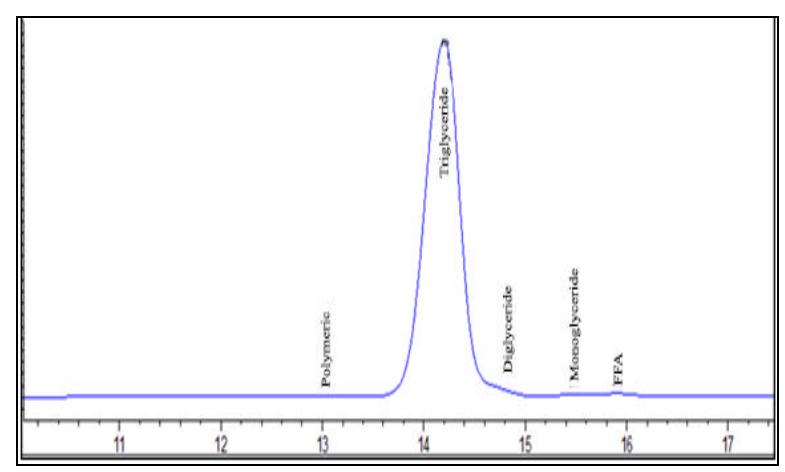

Figure 2. Total Polymeric Substance Chromatogram for Ficus Carica Seed Oil

\section{Conclusion}

Free fatty acid, peroxide value, conjugated diene and triene amounts, chlorophyll, $\quad \beta$-carotene, fatty acid composition, triglyceride, tocol (tocopherol and tocotrienol) compositions, sterol, wax and total polymeric compounds are important parameters for determination of chemical properties of edible seed oils. The current results show that cold pressed ficus carica seed oil has a low content of free fatty acid, peroxide value, conjugated diene and triene, chlorophyll, wax and total polymeric compounds. In contrast, it has a high content of linolonic acid, $\beta$-carotene, tocol (tocopherol and tocotrienol) and sterol with high nutritional value and beneficial phytochemicals. It is also good source of LLnLn, LnLnLn, OLLn, LLLn and PLLn containing linolenic and linoleic acid which are polyunsaturated fatty acids. In conclusion, this study was showed that ficus carica seed oil could be used as a vegetable and medical oil with superior properties.

\section{Conflict of Interest}

The authors have no conflict of interest.

\section{Acknowledgment}

This study, a part of M.Sc. work entitled "Examination of The Properties of Fig and Rosehip Seed Oils Obtained by Cold Pressing Method", was supported by Selcuk University Coordinators of Scientific Research with SUBAP 17201003 project numbers. The authors wish to thank the principal of Selcuk University and Scientific Research Projects Coordination.

\section{References}

1. E. Duman, M. Şimşek and M. M. Özcan, J. Agric. Proces. Technol., 24 (2018) 75.

2. S. N. Vemmos, E. Petri and V. Stournaras, Sci. Hortic., 160 (2013) 198. https://doi.org/10.1016/j.scienta.2013.05.036

3. E. Nakilcioğlu-Taş, J. Agric. Sci., 25 (2019) 232.

https://doi.org/10.15832/ankutbd.398268

4. L. Hssaini, H. Hanine, J. Charafi, R. Razouk, A. Elantari, S. Ennahli, F. Hernández and R. Ouaabou, Oilseeds Fats Crop. Lipid., 27 (2020) 1. https://doi.org/10.1051/ocl/2020003

5. H. F. Ayyildiz, M. Topkafa, H. Kara, S. T. H. Sherazi, Int. J. Food Prop., 18 (2015) 2064.

https://doi.org/10.1080/10942912.2014.962657

6. M. Topkafa, Anal. Method., 8 (2016) 4220.

https://doi.org/10.1039/C6AY00709K

7. F. Fine, C. Brochet, M. Gaud, P. Carre, N. Simon, F. Ramli, F. Joffre, Eur. J. Lipid Sci. Technol., 118 (2016) 680. https://doi.org/10.1002/ejlt.201400400

8. T. D. Parker, D. Adams, K. Zhou, M. Harris and L.Yu, J. Food Sci., 68 (2003) 1240.

https://doi.org/10.1111/j.13652621.2003.tb09632.x

9. B. Matthäus and L. Brühl Food/Nahrung., 47 (2003) 413. https://doi.org/10.1002/food.200390092 
10. G. de Sousa Ferreira Soares, VdM. Gomes, A. dos Reis Albuquerque, M. Barbosa Dantas, R. Rosenhain, AGd. Souza, DC. Persunh, CAdA. Gadelha, MJdC. Costa and TS. Gadelha, Sci. World J., (2012)1.

https://doi.org/10.1100/2012/847471

11. J. Parry, Z. Hao, M. Luther, L. Su, K. Zhou and L. L. Yu, J. Am. Oil Chem.' Soc., 83 (2006) 847.

https://doi.org/10.1007/s11746-006-5036-8

12. M. F. Ramadan, Ind. Crop. Prod., 43 (2013) 65.

https://doi.org/10.1016/j.indcrop.2012.07.013

13. M. Topkafa, H. F. Ayyildiz and H. Kara, J. Iran. Chem. Soc., (2021) 1. https://doi.org/10.1007/s13738-021-02186-z

14. J. A. Simon, Y-H. Chen and S. Bent, Am. J. Clin. Nutr., 89 (2009) 1558S. https://doi.org/10.3945/ajcn.2009.26736E

15. I. A. Brouwer, M. B. Katan and P. L. Zock. The J. Nutr., 134 (2004) 919. https://doi.org/10.1093/jn/134.4.919

16. K. Fekete, E. Györei, S. Lohner, E. Verduci, C. Agostoni and T. Decsi. Obesity Rev., 16 (2015) 488.

https://doi.org/10.1111/obr.12280

17. S. Žilić, J. M. Dragišić, V. Maksimović, M. Maksimović, Z. Basić, M. Crevar and G. Stanković. Helia., 33 (2010) 75. https://doi.org/10.2298/hel1052075z

18. M. Topkafa. J. Iran. Chem. Soc., 17 (2020) 3383.

https://doi.org/10.1007/s13738-020-01996-x

19. Republic of Turkey MoAaF (2012) Türk Gıda Kodeksi Bitki Adı ile Anılan Yağlar Tebliği.

https://www.resmigazete.gov.tr/eskiler/2 012/04/20120412-7.htm.

20. Society AOC (1998) Official methods and recommended practices of the American Oil Chemists' Society. American Oil Chemists Society USD.

21. H. Regulation, (1991). Commission Regulation (EEC) No. 2568/91 of 11 July 1991 on the characteristics of olive oil and olive-residue oil and on the relevant methods of analysis Official Journal L., 5 September. Offic. J. L., 248 (1991) 1.

22. AB ALS (1995) Methods for Analysis Application General Manual MA 0901. Alfa Laval Separation AB, Tumba, Sweden.

23. M. Tsimidou, D. Boskou, Spices, herbs and edible fungi. Elsevier, Amsterdam, (1994) 273.

24. R. Suzuki, R. Noguchi, T. Ota, M. Abe, K. Miyashita and T. Kawada, Lipids, 36 (2001) 477. https://doi.org/10.1007/s11745-001-0746-0

25. M. Topkafa, H. Kara and S. T. H. Sherazi, J. Am. Oil Chem. Soc., 92 (2015) 791. https://doi.org/10.1007/s11746-015-2652-1

26. M. Topkafa and H. F. Ayyildiz. Int. J. Food Prop., 20 (2017) 198. https://doi.org/10.1080/10942912.2016.1152481

27. International Olive Oil Council (2003) Method of Analysis Determination of Wax Content by Capillary Column Gas Chromatography, vol COI/T.20/Doc. no.18/ Rev. 2. Madrid, Spain

28. F. N. Arslan, H. Kara, H. F. Ayyildiz, M. Topkafa, I. Tarhan and A. Kenar. $J$. Am. Oil Chem. Soc., 90 (2013) 1179. https://doi.org/10.1007/s11746-013-2266-4

29. N. Güven, A. Gökyer, A. Koç, N. N. Temiz, S. Selvi, B. Koparal, B. Deniz, SBÖ. Dedeoğlu, H. F. Büyükhelvacigil and R. Büyükhelvacigil, J. Pharm. Pharmacol., 7 (2019) 541. doi: 10.17265/2328-2150/2019.10.003

30. L. Yu, S. Haley, J. Perret, M. Harris, J. Wilson and M. Qian, J. Agric. Food Chem., 50 (2002) 1619. https://doi.org/10.1021/jf010964p

31. N. Baygeldi, Ö. Küçükerdönmez, R.N. Akder and Ö. Çağındı, Progr. Nutr., 23 (2021) IN PRESS.

32. S. Martini and M. An, J. Am. Oil Chem. Soc., 77 (2000) 1087. https://doi.org/10.1007/s11746-000-0171-9 